Information on the advantages of fixation is helpful, but all decisions must be tempered with a concern to do no harm.

MALCOM F. MACNICOL

\section{REFERENCES}

1. Newton PO, Mubarak SJ. Financial aspects of femoral shaft fracture treatment in children and adolescents. J Pediatr Orthop 1994;14: 508-12.
2. Wallace ME, Hoffman EB. Remodelling of angular deformity after femoral shaft fractures in children. J Bone Joint Surg [Br] 1992; 74-B:765-9.

3. Raney EM, Ogden JA, Grogan DP. Premature greater trochanteric epiphysiodesis secondary to intramedullary femoral rodding. $J$ Pediatr Orthop 1993;13:516-20.

4. O'Malley DE, Mazuk JM, Cummings RJ. Femoral head avascular necrosis with intramedullary nailing in an adolescent. $J$ Pediatr Orthop 1995;15:21-3.

\title{
Planovalgus and cavovarus deformity of the hind foot
}

A functional approach to management

To function correctly the foot and ankle require articular stability and normal alignment. The talus occupies a key position since it has no muscle attachments and $70 \%$ of its surface is covered by articular cartilage. Its stability depends on ligaments and the action of extrinsic and intrinsic muscles.

Many deformities of the foot arise in the hind foot; both varus and valgus may be caused by imbalance of the extrinsic muscles. In a child the capacity for bone and articular remodelling may allow correction by soft-tissue release and tendon transfers, but in an adult bony procedures are required.

\section{MORPHOLOGICAL PRINCIPLES}

A comparison of the hip with the joints of the hind foot shows similarities. ${ }^{1,2}$ The hip is a ball-and-socket joint or 'enarthrosis' as is the talocalcaneonavicular joint. ${ }^{3}$ Principles already well-established for the management of hip deformities could be effective for deformities of the hind foot.

In the hip the femoral head lies against the concave cartilaginous surface of the acetabulum. This is part of a sphere with a horseshoe-shaped articular surface, consisting of the pubis anteriorly, the ilium superiorly and the ischium posteriorly. When these bones fuse in adolescence, the ischial and pubic parts remain linked inferiorly by the strong transverse ligament. ${ }^{4}$

In the foot, the head of the talus lies against a concave

K. Klaue, MD, Associate Professor

ATOS Klinik, Department of Orthopaedic Surgery, Bismarckstrasse 9-15, 69115 Heidelberg, Germany.

(C)1997 British Editorial Society of Bone and Joint Surgery 0301-620X/97/67195 \$2.00

J Bone Joint Surg [Br] 1997;79-B:892-5. cartilaginous surface which is also horseshoe-shaped. The navicular facet lies anteriorly, the anterior facet of the calcaneum is in the middle, and the sustentaculum tali supports the talus inferiorly and posteriorly. Laterally, these structures are bound together by a section of the ligamentum bifurcatum, and below by the spring ligament between the navicular and the sustentaculum tali. The talocalcaneonavicular joint is therefore also a ball-andsocket joint which allows mobility in the frontal plane. Its functional anatomy is similar to that of the hip.

Distal to this ball and socket, the anatomy of the foot can be considered as consisting of medial and lateral columns. The medial column is analagous to the 'femoral' part of the combined joint. Its socket, the calcaneonavicular cup, continues as the three cuneiforms, the three first metatarsals, and the corresponding toes. The lateral column comprises the calcaneum, the cuboid, and the two lateral rays. The function of the subtalar joint depends on the division of load between these columns, and any imbalance will cause deformity.

Loss of movement proximally as a result of triple arthrodesis may lead to abnormal movement and degenerative changes in the neighbouring joints, the ankle and the joints of the midfoot. ${ }^{5}$

\section{PATHOLOGY}

The principal deformities of the hind foot are varus-cavusadductus (club foot) and valgus-planus-abductus (flat foot).

Varus deformity. In the hip, acetabular dysplasia reduces the cover of the femoral head, and in children progressive plastic deformation may remodel the cavity from its normal cotyloid shape into an ovoid. ${ }^{6}$ A similar deformation may occur in club foot due to prenatal muscle imbalance. ${ }^{7}$ In the frontal plane the head of the talus moves laterally and the calcaneonavicular cup becomes an ovoid. The forefoot inclines medially, creating a talometatarsal angle which is 


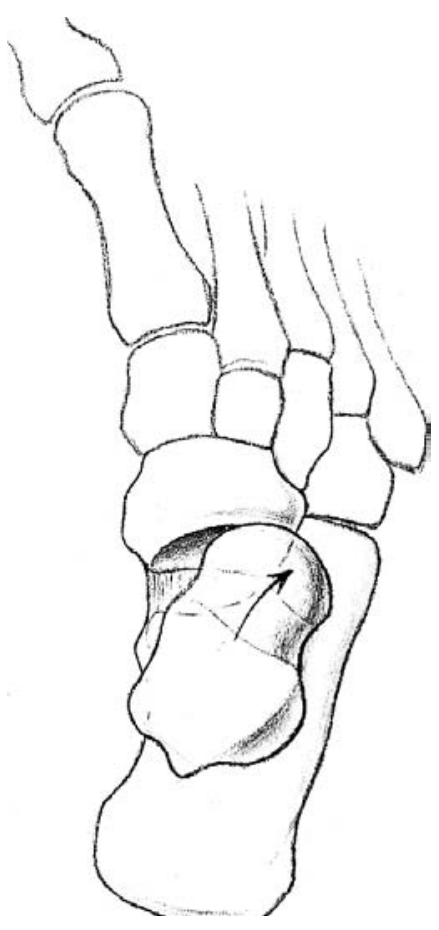

Fig. 1a

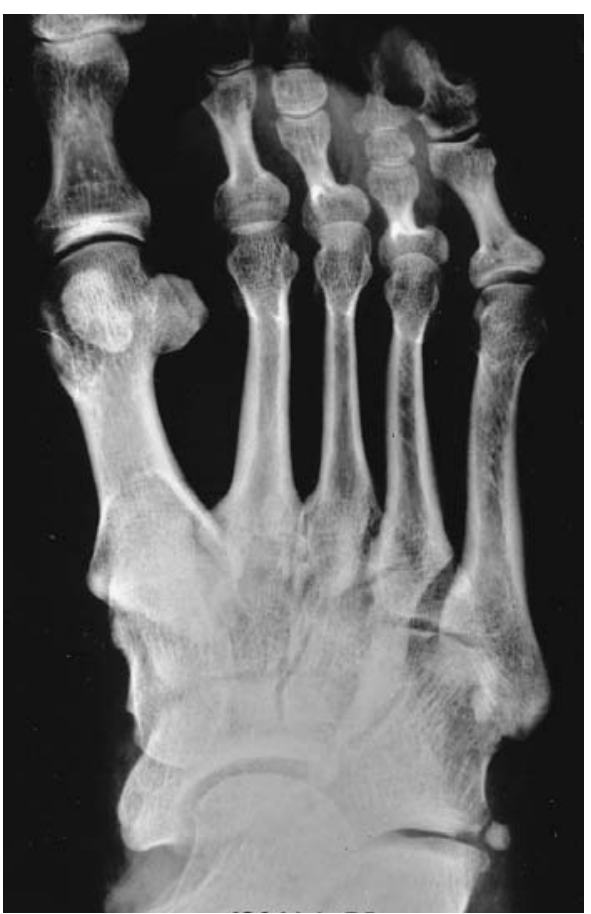

Fig. 1b

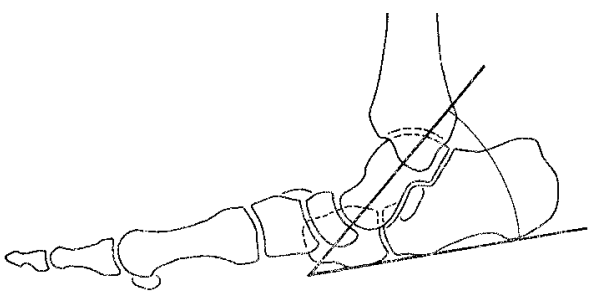

Fig. 2

Diagram of a flat foot. On the medial side the distance between the sustentaculum tali and navicular is increased thus allowing the head of the talus to protrude.
Diagram to show the position of the talus in a club foot.

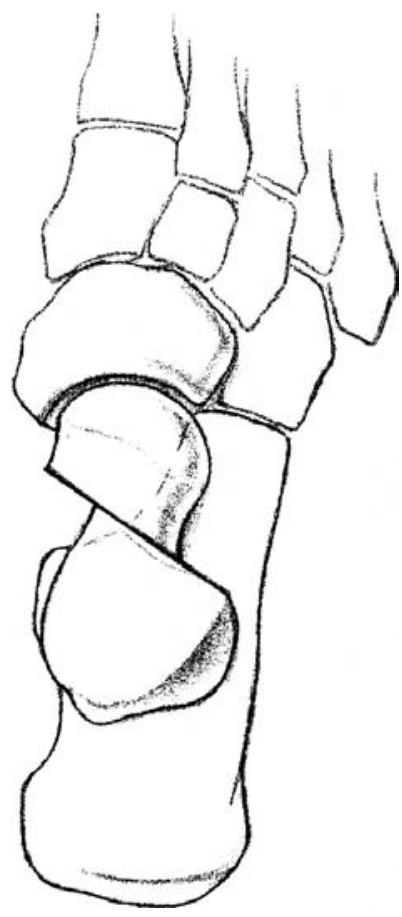

Fig. 3a

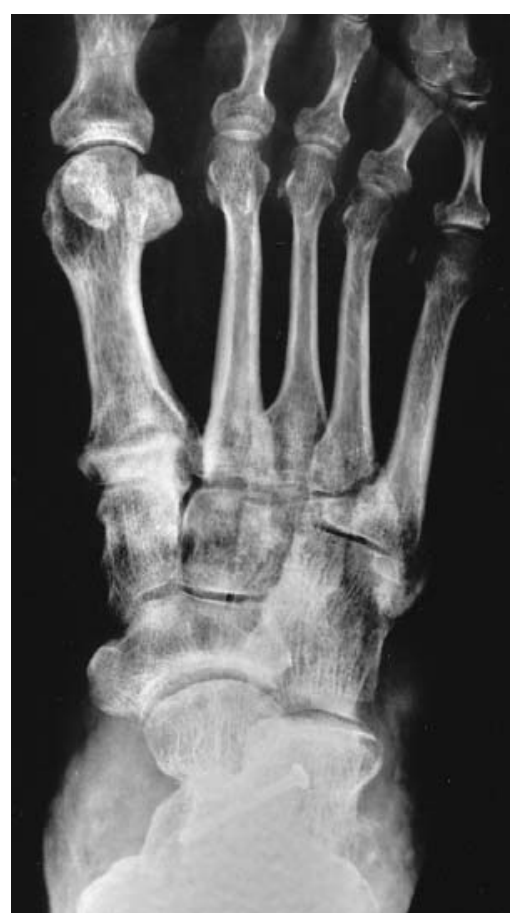

Fig. 3b
Figure 3a - Osteotomy of the neck of the talus in cavovarus deformity allows for medial and plantar translation of the head within the acetabulum pedis. Figure $3 b-$ Anteroposterior radiograph after osteotomy of the neck of the talus. convex laterally (Fig. 1). The apex of this deformity is the calcaneocuboid joint. ${ }^{8}$ In the sagittal plane, the talometatarsal angle becomes convex superiorly, thus creating the cavus component of the deformity.

Valgus deformity. At the hip, a deficient acetabular floor may allow the femoral head to protrude medially, leading to degenerative changes in the deep central cartilage, while the articular cartilage at the mouth of the acetabulum remains intact (protrusio acetabuli).

The parallel situation in the foot is seen when the floor of 
the calcaneonavicular cup is deficient. The joint between the navicular and the sustentaculum tali widens medially and the talar head protrudes into this space. There are many causes, including chronic insufficiency or rupture of the tibialis posterior tendon. ${ }^{9}$ Talar protrusion produces a flat foot, in which the forefoot inclines laterally and the talometatarsal angle becomes convex medially thus producing the abductus-valgus component of the deformity. In the sagittal plane, the angle is convex on the plantar aspect, the hind foot as a whole moves into equinus and tendo Achillis may become contracted (Fig. 2).

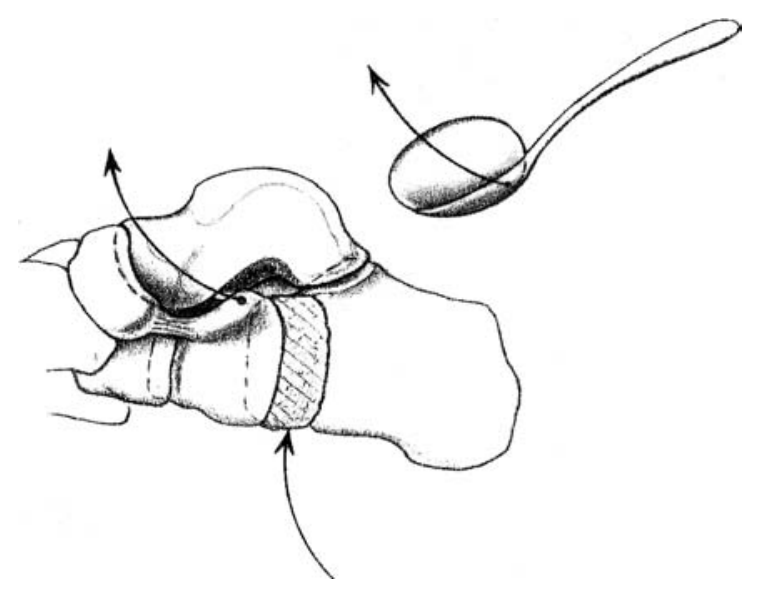

Fig. 4a

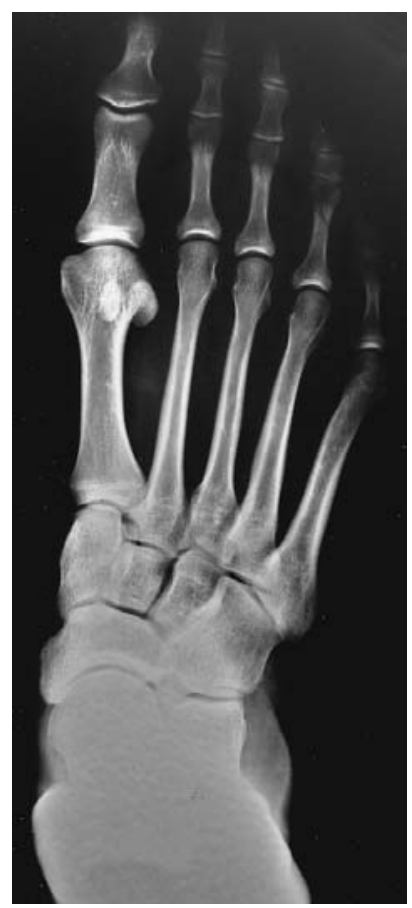

Fig. $4 \mathrm{~b}$

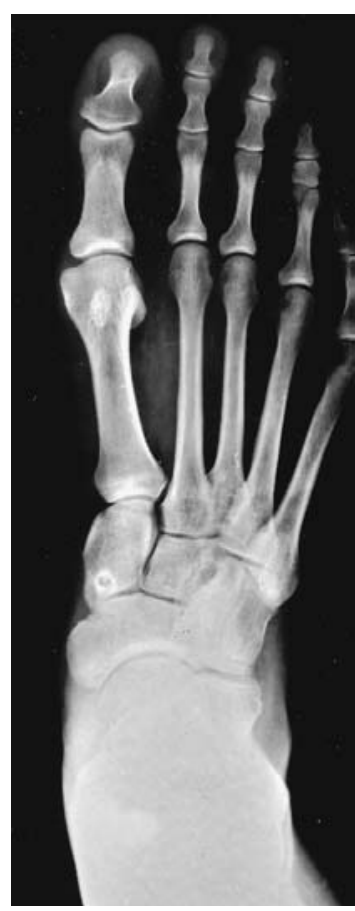

Fig. $4 \mathrm{c}$

\section{PRINCIPLES OF SURGICAL CORRECTION}

Deformity of the hind foot involves all the joints between the tibia and the navicular and cuboid. Before correction it is essential to confirm that the ankle is accurately aligned in the frontal plane, that is within a range of -4 to $+4^{\circ}$ of horizontal.

At the hip, osteotomies to correct deformity are best placed at the site of the deformity, or as near to it as possible ${ }^{10,11}$ and similar principles may be applied to the talocalcaneonavicular joints in the foot.

For varus deformities, subluxation of the talar head can be reduced by lengthening the medial column, preferably at the talar neck. For valgus deformities, the protrusion of the talar head within the calcaneonavicular cup can be reduced by lengthening the lateral column.

Surgical correction of club foot. In young children, surgical correction of club foot concentrates on specific softtissue releases to overcome key deformities, ${ }^{12,13}$ but in older children a similar deformity will require bony correction. Evans ${ }^{14}$ corrected club feet by shortening the lateral column; he removed a laterally-based wedge and fused the calcaneocuboid joint. Roberts (personal communication) has proposed a transverse talar neck osteotomy (with bone block) to lengthen the talus. With correct orientation of the osteotomy, the head of the talus can be moved inferiorly, medially and forwards to gain reduction within the socket and realign it on the first metatarsal. The displacements are

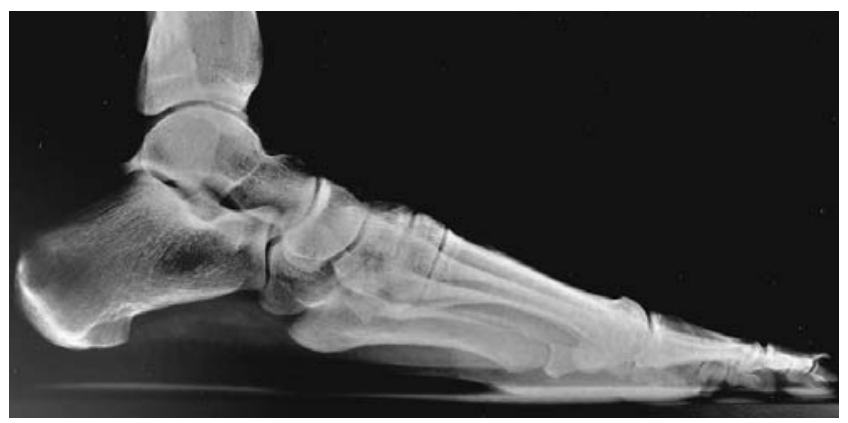

Fig. $4 d$

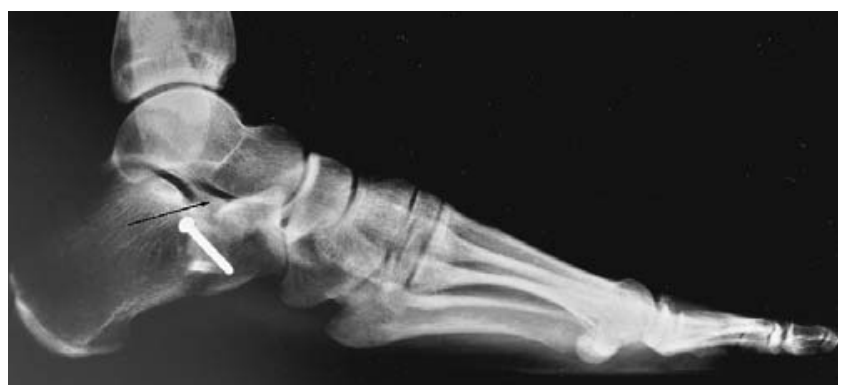

Fig. $4 \mathrm{e}$

Figure $4 \mathrm{a}$ - Diagram showing that elongation of the calcaneum in planovalgus deformity allows the sustentaculum tali to lift the anterior talus like an egg within a spoon. Figures $4 \mathrm{~b}$ and $4 \mathrm{c}-$ Anteroposterior radiographs showing pre- and postoperative alignment of the acetabulum pedis. Figure $4 \mathrm{~d}-$ Lateral preoperative radiograph showing that the talometatarsal axis is broken. Figure $4 \mathrm{e}-$ Lateral postoperative radiograph after the calcaneus had been lengthened shows that the talometatarsal axis has been restored. 
the converse of the deformities and aim to flatten the cavus element, lateralise the midfoot, and pronate the forefoot (Fig. 3).

Lengthening of the talar neck can be achieved through either a medial or a lateral approach. A lateral approach (Ollier) preserves a better blood supply to the talar head and medial soft-tissue cover and allows for optimal precision. The osteotomy is oblique, starting laterally, at the line between the anterior extreme of the articular surfaces of the ankle above and the posterior facet of the subtalar joint below. An oscillating saw is used to make a cut directed at the posterior edge of the articular surface on the medial side of the talar head. The osteotomy is mobilised by careful use of a broad laminar spreader, and the talar head is pushed gently into adduction and plantar flexion, moving it in the osteotomy plane by about $10 \mathrm{~mm}$. An interposed bone graft may be needed laterally to increase the lengthening component of the osteotomy. In some cases of severe deformity, it may be necessary to reorientate the heel into valgus as a separate procedure. ${ }^{15}$

Surgical correction of flat foot. Surgical correction of flat foot in the adult is indicated only when function becomes severely impaired by pain. Lengthening of the lateral column moves the navicular medially, the protruding talar head is recaptured, and a normal talometatarsal angle is created. The medial arch of the foot rises from its flattened position, the peroneus longus tendon becomes tighter and the distal end of the first metatarsal moves downwards.

Lengthening of the lateral column can be achieved by an arthrodesis at the calcaneocuboid joint, with an interposed bone block (Hansen, personal communication). In children this effect has been achieved by elongation of the calcaneum by insertion of a bone graft through an osteotomy immediately proximal to the calcaneocuboid joint. ${ }^{16,17}$

In flat foot, protrusion of the talar head is plantarwards into the widened 'fossa acetabuli'. The body of the talus glides to the bottom of the posterior subtalar facet and may cause painful bony impingement at Gissane's angle. A better site for a lengthening osteotomy is behind the sustentaculum through the sinus tarsi. This retroacetabular osteotomy of the calcaneum with an interposed bone block will tend to lift the medial arch and therefore the talar head, as a spoon lifts an egg (Fig. 4a). The posterior facet of the talus is reorientated to its corresponding calcaneal surface and the proper dimensions of the sinus tarsi are restored. Interosseous impingement is prevented. True functional mobility of the talus on the calcaneum is restored to give helicoidal glide, ${ }^{18}$ and the talocalcaneonavicular joint is made congruent. Repositioning the talocalcaneonavicular socket around the talus together with the necessary lengthening of the heel cord reorientates the ankle and the lower limb to their physiological alignment (Figs $4 \mathrm{~b}$ to $4 \mathrm{e}$ ).

We have applied the principles of a lengthening osteot- omy of the talus, calcaneocuboid lengthening arthrodesis, and calcaneal lengthening osteotomy for seven years and have performed 13 osteotomies to lengthen the neck of the talus in 11 patients, 11 calcaneocuboid lengthening arthrodeses in ten, and six calcaneal lengthening osteotomies in six. The early results are satisfactory but the limited followup does not allow firm conclusions at this stage.

We believe that the principle of producing stability by correction of the weight-bearing cup of the foot at the talocalcaneonavicular joint is logical, but it is essential to correct muscle imbalance at the same time to prevent relapse of the correction. ${ }^{19}$

\section{K. KLAUE}

We are especially grateful to Dr D. A. Reynolds, FRCS, St Thomas' Hospital, London for his thorough review of our paper and his considerable contribution to its presentation. We also thank Dr S. T. Hansen Jr of Seattle (USA) for his logical teaching in foot and ankle surgery. This work would not have been possible without his intellectual input.

\section{REFERENCES}

1. Coppens Y. The anatomical and functional origin of the first bipedalism. Bull Acad Natl Med 1991;175:977-93.

2. Hinrichsen KV, Jacob HJ, Jacob M, et al. Principles of ontogenesis of leg and foot in man. Anat Anz 1994;176:121-30.

3. Pisani G. The coxa pedis. Eur J Foot Ankle Surg 1994;1:67-74.

4. Lohe F, Eckstein F, Putz R. Stress on the ligamentum transversum acetabuli in physiological stress on the hip joint. Unfallchirurg 1994; 97:445-9.

5. Angus PD, Cowell HR. Triple arthrodesis: a critical long-term review. J Bone Joint Surg [Br] 1986;68-B:260-5.

6. Rejholec M, Stryhal F. Behavior of the proximal femur during the treatment of congenital dysplasia of the hip: a clinical long-term study. J Pediatr Orthop 1991;11:506-13.

7. Drvaric DM, Kuivila TE, Roberts JM. Congenital clubfoot: etiology, pathoanatomy, pathogenesis and the changing spectrum of early management. Orthop Clin North Am 1989;20:641-7.

8. Thometz JG, Simons GW. Deformity of the calcaneocuboid joint in patients who have talipes equinovarus. J Bone Joint Surg [Am] 1993; 75-A:190-5.

9. Klaue K. Rupture of the degenerated tibialis posterior tendon: symptoms and treatment. Ther Umsch 1991;48:796-802.

10. Müller ME Intertrochanteric osteotomy: indication, preoperative planning technique. In: Schatzker J, ed. The intertrochanteric osteotomy. Berlin, etc: Springer Verlag, 1984:25-66.

11. Tönnis D. Indications and time planning for operative interventions in hip dysplasia in child and adulthood. Z Orthop 1985;123:458-61.

12. Malan MM. Principles of operative correction of congenital clubfoot deformity. Foot and Ankle Surgery 1996;2:50-1.

13. Simons GW. Complete subtalar release in club feet. Part I. A preliminary report. J Bone Joint Surg [Am] 1985;67-A:1044-55.

14. Evans D. Relapsed club foot. J Bone Joint Surg [Br] 1961;43-B: 722-33.

15. Dwyer FC. The treatment of relapsed club foot by the insertion of a wedge into the calcaneum. J Bone Joint Surg [Br] 1963;45:67-75.

16. Evans D. Calcaneo-valgus deformity. J Bone Joint Surg [Br] 1976; 58-B:90-3.

17. Sangeorzan BJ, Mosca V, Hansen ST. Effect of calcaneal lengthening on relationships among the hindfoot, midfoot and forefoot. Foot Ankle 1993;14:136-41.

18. Sarrafian SK. Anatomy of the foot and ankle. 2nd ed. Philadelphia: Lippincott, 1993:513-21.

19. Wetmore RS, Drennan JC. Long-term results of triple arthrodesis in Charcot-Marie-Tooth disease. J Bone Joint Surg [Am] 1989;71-A: $417-22$. 